\title{
Maternal gene polymorphisms involved in folate metabolism as risk factors for Down syndrome offspring in Southern Brazil
}

\author{
Ana Paula Carneiro Brandalize $e^{a, b, c}$, Eliane Bandinellii ${ }^{a}$ Pollyanna Almeida Dos Santos ${ }^{a, b}$ and \\ Lavínia Schüler-Faccini ${ }^{\mathrm{a}, \mathrm{b}, \mathrm{c}, *}$ \\ ${ }^{a}$ Departamento de Genética, Universidade Federal do Rio Grande do Sul, Porto Alegre, Brasil \\ b Programa de Pós-Graduação em Genética e Biologia Molecular, Universidade Federal do Rio Grande do Sul, \\ Porto Alegre, Brasil \\ ' Serviço de Genética Médica, Hospital de Clínicas de Porto Alegre, Porto Alegre, Brasil
}

\begin{abstract}
This study aimed to investigate the role of maternal polymorphisms, as well as their risk genotypes combinations of MTR A2756G, MTRR A66G, CBS 844ins68, and RFC A80G, involved in folate/homocysteine metabolism, as possible risk factors for Down syndrome (DS) in Southern Brazil. A case-control study was conducted with 239 mothers of DS children and 197 control mothers. The investigation of polymorphisms was performed by PCR and PCR-RFLP. The distribution of genotypic variants was similar in both groups when they were analyzed separately. An investigation of combined risk genotypes showed that the risk of having a DS child for one, two or three risk genotypes was $6.23,6.96$ and 5.84 (95\%CI 1.48-26.26; 1.69-28.66; 1.37-24.86), respectively. The combined MTRR 66G and MTHFR 677T alleles were significantly more common among mothers of children with DS than among control mothers (OR 1.55; IC 95\% 1.03-2.35). The results show that individual polymorphisms studied in this work are not associated with DS; however, the effects of the combined risk genotypes among $M T R, M T R R, C B S$ and $R F C$ genes are considered maternal risk factors for DS offspring in our population.
\end{abstract}

Keywords: Down syndrome, folate, MTR, MTRR, CBS, RFC

\section{Introduction}

First described in 1866, Down syndrome (DS) is the most common genetic cause of mental retardation, with a prevalence of one in 700-800 live-born children [3]. It is characterized by trisomy of chromosome 21 , which in $95 \%$ of cases is due to non-disjunction in maternal meiosis [20]. The factors responsible for trisomy 21 are under intense investigation, but the only established etiological factor related to chromosome nondisjunction in humans is advanced maternal age

\footnotetext{
*Corresponding author: Lavinia Schuler-Faccini, Universidade Federal do Rio Grande do Sul - Departamento de Genética, Caixa Postal 15031 - Agencia Campus UFRGS, CEP 91501-970 / Porto Alegre, RS, Brasil. Tel.: +51 33166727; Fax: +51 33167311; Email: lavinia.faccini@ufrgs.br.
}

at conception [1]. Maternal polymorphisms linked to folate metabolism have been studied as a risk factor for DS. James and colleagues [4] hypothesized that aberrant DNA methylation patterns resulting from abnormal folate metabolism, due to polymorphisms in enzymes involved in this metabolic pathway, may increase hypomethylation of centromeric and pericentromeric regions, affecting non-disjunction rates. Decreased amounts of folate and methyl donor groups may result in DNA hypomethylation, DNA breaks, and abnormal chromosome segregation $[4,16]$.

The folate metabolism begins with the intake of folic acid through diet. It is rapidly reduced to its active form, tetrahydrofolate, which converts to 5,10methylenetetrahydrofolate by the enzyme methylenetetrahydrofolate reductase, encoded by the MTHFR gene [14]. This substrate is vital for nucleic acids metabolism, including those necessary for synthesis of 
nucleotides and consequent cell division [2]. The product of this reaction is methyl groups used for the synthesis of methionine, necessary for DNA methylation. Subsequently, the enzyme methionine synthase, encoded by the MTR gene, catalyzes the remethylation of homocysteine to methionine, necessary for the production of S-adenosylmethionine, the universal methyl donor. Vitamin $\mathrm{B}_{12}$ acts as a cofactor for methylation [22]. It becomes oxidized over time and the enzyme methionine synthase is inactivated. Functional regeneration of this methionine synthase requires the participation of another enzyme, methionine synthase reductase, which is encoded by the MTRR gene [23]. Cystathioninebeta-synthase $(C B S)$ acts in the transulfuration of homocysteine to cystathionine, playing a critical role in linking the folate and methionine cycles in regulating homocysteine levels [9]. Another important protein involved in this metabolism is folate-transporting protein $(R F C-1)$, transporting 5-methyltetrahydrofolate into the cells [26].

Polymorphisms involved in this metabolism have been studied as maternal risk factors for DS. Conflicting results have emerged in studies when evaluating the association between single polymorphisms in genes involved in folate metabolism and risk for DS. It is possible that the combined presence of two or more polymorphisms in the genome could increase the maternal DS risk [3,6,12,15,24,30,31].

The enzyme 5,10-methylenetetrahydrofolate plays an important role in folate metabolism; some studies have shown that polymorphisms in the MTHFR gene could be a factor contributing to increased chance of having a DS child $[15,17,25,29,31,32]$. Our recent work suggested an association between the C677T MTHFR polymorphism and the risk of having a child with DS [7]. In the present study, we have extended our previous work to analyze polymorphisms in genes encoding for enzymes other than MTHFR which are also involved in the folate metabolic pathway. We analyzed the role of MTR A2756G, MTRR A66G, CBS 844ins68, and $R F C$ A80G polymorphisms as maternal risk factors for DS, as well as their gene-gene combination effect between these polymorphisms and MTHFR C677T, previously studied by our group [7].

\section{Subjects and methods}

\subsection{Subjects}

All DS cases were identified and ascertained through the Genetics Service of HCPA (Clinical Hospital of Por- to Alegre) and local DS support-groups (APAEs). The control group consisted of healthy children's mothers that were randomly selected to participate in the study during blood collection for routine laboratory analyses at HCPA. The case-control study was conducted with 239 case mothers and 197 control mothers, all eurodescendent. More details of case and control selection can be found in a previous study developed by our group [7].

This study was approved by the Research Ethics Committee of HCPA. Informed consent was obtained from all mothers who participated in the study. After signature of informed consent, $5 \mathrm{ml}$ peripheral blood was collected in EDTA tubes for genetic analyses. Samples were collected from June 2005 to May 2007.

\subsection{Analysis of polymorphisms}

DNA was extracted from blood samples as described by Lahiri and Nurnberger [21]. MTR A2756G, MTRR A66G, $C B S$ 844ins68, and RFC A80G polymorphisms were analyzed by polymerase chain reaction (PCR), with primers and protocols already described by Van der Put and cols, Brown and cols, Kluijtmans and cols, Winkelmaver and cols, respectively $[8,19,33,34]$. The amplified fragments of genes MTR, MTRR and RFC were cleaved with HaeIII, NdeI and CfoI, respectively, and visualized on $6 \%$ polyacrylamide gel. The PCR fragments relative to polymorphisms of the $C B S$ gene were visualized on $2 \%$ agarose gel.

\subsection{Use of statistics}

Analyses were performed with SPSS 10.0 statistical package for Windows. The Chi-square $\left(\chi^{2}\right)$ was used to test for deviation from Hardy-Weinberg equilibrium and to compare allelic and genotypic frequencies between groups. The odds ratio (OR) and 95\% confidence intervals $(\mathrm{CI})$ were determined to measure possible effects of having one, two, three, or four risk genotypes. Logistic regression models were used to control the effect of maternal age at the time of having a DS. A dichotomous variable was used $(<35$ and $\geqslant 35$ year) because of its stronger effect on Down syndrome prevalence among women over 35 years of age. A Bonferroni correction was applied for multiple testing. The significance level was considered for $p<0.05$ values. 
Table 1

Distribution of genotypic and allelic frequencies in case and control groups

\begin{tabular}{|c|c|c|c|c|c|c|}
\hline \multirow[t]{2}{*}{ Genotype } & \multicolumn{2}{|c|}{ Case } & \multicolumn{2}{|c|}{ Control } & \multirow[t]{2}{*}{$\mathrm{p}$} & \multirow[t]{2}{*}{$\mathrm{p}^{*}$} \\
\hline & $\mathrm{n}$ & $\%$ & $\mathrm{n}$ & $\%$ & & \\
\hline \multicolumn{7}{|l|}{ MTRA2756G } \\
\hline AA & 159 & 66.5 & 130 & 66 & 0.890 & 0.838 \\
\hline $\mathrm{AG}$ & 71 & 29.7 & 61 & 31 & & \\
\hline GG & 9 & 3.8 & 6 & 3 & & \\
\hline G frequency & \multicolumn{2}{|c|}{0.18} & \multicolumn{2}{|c|}{0.19} & & \\
\hline \multicolumn{7}{|l|}{ MTRRA66G } \\
\hline AA & 42 & 17.6 & 42 & 21.3 & 0.562 & 0.271 \\
\hline AG & 137 & 57.3 & 111 & 56.3 & & \\
\hline GG & 60 & 25.1 & 44 & 22.4 & & \\
\hline $\mathrm{G}$ frequency & \multicolumn{2}{|c|}{0.46} & \multicolumn{2}{|c|}{0.49} & & \\
\hline \multicolumn{7}{|l|}{$R F C \mathbf{A 8 0 G}$} \\
\hline AA & 73 & 30.5 & 64 & 32.5 & 0.363 & 0.750 \\
\hline AG & 101 & 42.3 & 91 & 46.2 & & \\
\hline GG & 65 & 27.2 & 42 & 21.3 & & \\
\hline $\mathrm{G}$ frequency & \multicolumn{2}{|c|}{0.48} & \multicolumn{2}{|c|}{0.44} & & \\
\hline \multicolumn{7}{|l|}{$C B S$} \\
\hline Ins $-I-$ & 207 & 86.6 & 169 & 85.8 & 0.947 & 0.190 \\
\hline Ins $+/-$ & 28 & 11.7 & 25 & 12.7 & & \\
\hline Ins $+/+$ & 4 & 1.7 & 3 & 1.5 & & \\
\hline+ frequency & \multicolumn{2}{|c|}{0.08} & \multicolumn{2}{|c|}{0.08} & & \\
\hline
\end{tabular}

\section{Results}

A total of 239 case mothers and 197 control mothers participated in the study. Maternal age, as expected, was higher in the case group, with a higher incidence of mothers older than 35 years (case $=121$; control $=$ 29; $p=0.00001$ ).

Table 1 presents the distribution of genotypes and allelic frequency for MTR A2756G, MTRR A66G, CBS 844ins68, and RFC A80G among case and control individuals. The distribution of genotypes for these polymorphisms was in Hardy-Weinberg equilibrium in controls. In the case group, the distribution of genotypes for polymorphisms in genes $\operatorname{MTRR}\left(\chi_{1}^{2}=5.59 ; p=\right.$ $0.02), \operatorname{CBS}\left(\chi_{1}^{2}=6.03 ; p=0.01\right)$ and $R F C\left(\chi_{1}^{2}=5.66\right.$; $p=0.02$ ) was not in Hardy-Weinberg equilibrium.

The results did not show any individual association between these polymorphisms and DS. The genotypic frequencies of MTR 2756GG, MTRR 66GG, CBS 844ins68, and $R F C$ 80GG polymorphisms were not significantly higher among mothers of DS children (3.8\%; $25.1 \% ; 1.7 \% ; 27.2 \%$, respectively) than among controls $(3.0 \% ; 22.4 \% ; 1.5 \% ; 21.3 \%$, respectively), even after adjustment for maternal age.

The gene-gene effect was analyzed by the combination of risk genotypes (MTR $\mathrm{AG}+\mathrm{GG}$ and/or $M T R R$ $\mathrm{AG}+\mathrm{GG}$ and/or $R F C \mathrm{AG}+\mathrm{GG}$ and/or $C B S$ Ins $+/-$ $++/+$ ) observed in case and control groups by comparing the presence of one to four risk genotypes with those without any risk genotype. As shown in Table 2, the risk of having a child with DS was 4.62, 5.02, and 4.25-fold higher for case mothers with one, two, or three risk genotypes, respectively, than for control mothers ( $p=0.032,0.018$ and 0.049 , respectively). When combined risk genotypes were adjusted for age, the risk increased to $6.23,6.96$, and 5.84 ( $p=0.130$, 0.001 and 0.02 , respectively).

Our previous published results of MTHFR C677T genotypes were included in a more complex model that analyzed the combined presence of the MTHFR $677 \mathrm{~T}$ allele and other polymorphic alleles obtained in the present study (Table 3 ). The results indicated that the simultaneous presence of MTHFR 677T and MTRR $66 \mathrm{G}$ polymorphism conferred a 1.55 fold increased risk for having a child with DS when adjusted for maternal age (95\% CI 1.03-2.35).

\section{Discussion}

Studies on the role of polymorphisms in folate/homocysteine metabolism as a risk factor for DS have obtained controversial results $[13,35]$. Most of these studies have investigated polymorphisms in the MTHFR gene. Little attention has been given to genes responsible for coding other enzymes involved in this metabolic pathway; in addition, it is possible that the 
Table 2

Combined risk genotypes analysis of $M T R, M T R R, R F C$, and $C B S$ polymorphisms in case and control groups

\begin{tabular}{lcccc}
\hline Genotype combinations & Case (\%) & Control $(\%)$ & OR (95\%CI) & adjusted OR \\
\hline Without any risk genotype $^{*}$ & $03(1.25)$ & $11(5.6)$ & Ref & Ref \\
With one risk genotype $^{\mathrm{a}}$ & $63(26.4)$ & $50(25.4)$ & $4.62(1.22-17.46)$ & $6.23(1.48-26.26)$ \\
With two risk genotypes $^{\mathrm{b}}$ & $115(48.1)$ & $84(42.6)$ & $5.02(1.36-18.55)$ & $6.96(1.69-28.66)$ \\
With three risk genotypes $^{\mathrm{c}}$ & $51(21.3)$ & $44(22.3)$ & $4.25(1.11-16.21)$ & $5.84(1.37-24.86)$ \\
With four risk genotypes $^{\mathrm{d}}$ & $07(3.0)$ & $08(4.1)$ & $3.21(0.63-16.38)$ & $4.81(0.83-28.06)$ \\
\hline
\end{tabular}

${ }^{\mathrm{a}} \operatorname{MTR}$ (AG or GG), MTRR (AG or GG),RFC (AG or GG) or $C B S$ (ins $+/-$ or $+/+$ );

${ }^{\mathrm{b}} \operatorname{MTR}(\mathrm{AG}$ or $\mathrm{GG})+M T R R(\mathrm{AG}$ or $\mathrm{GG}), M T R(\mathrm{AG}$ or $\mathrm{GG})+R F C$ (AG or GG), MTR (AG or

$\mathrm{GG})+C B S($ ins $+/-$ or $+/+$ ), MTRR (AG or GG) $+R F C(\mathrm{AG}$ or GG), MTRR (AG or GG) $+C B S$

(ins $+/-$ or $+/+$ ) or $R F C$ (AG or GG) $+C B S$ (ins $+/-$ or $+/+$ );

${ }^{\mathrm{c}} \operatorname{MTR}(\mathrm{AG}$ or GG) $+\operatorname{MTRR}(\mathrm{AG}$ or GG) $+R F C(\mathrm{AG}$ or GG), MTR (AG or GG) $+M T R R(\mathrm{AG}$ or GG) +

$C B S$ (ins $+/-$ or $+/+$ ) or MTRR (AG or GG) $+R F C$ (AG or GG) $+C B S($ ins $+/-$ or $+/+$ );

${ }^{d} \operatorname{MTR}(\mathrm{AG}$ or GG) $+\operatorname{MTRR}(\mathrm{AG}$ or GG) $+\operatorname{RFC}(\mathrm{AG}$ or GG) $+C B S(\mathrm{ins}+/-$ or $+/+$ ).

*The OR was adjusted for age by logistic regression.

Table 3

Combined MTHFR 677 (CT+TT) genotypes and other gene polymorphisms genotypes

\begin{tabular}{|c|c|c|c|c|c|}
\hline \multirow{3}{*}{ Polymorphisms } & \multicolumn{3}{|c|}{ MTHFR677T: presence of allele T } & \multirow{3}{*}{ OR $(95 \% \mathrm{IC})$} & \multirow{3}{*}{ adjusted OR } \\
\hline & \multirow[t]{2}{*}{ Allele } & \multicolumn{2}{|c|}{ Genotypic Frequency n (\%) } & & \\
\hline & & Case & Control & & \\
\hline \multirow[t]{2}{*}{ MTHFRA1298C } & $\mathrm{A}$ & $198(82.8)$ & $156(79.2)$ & Ref & Ref \\
\hline & $\mathrm{C}$ & $41(17.2)$ & $41(20.8)$ & $0.79(0.48-1.27)$ & $0.74(0.44-1.25)$ \\
\hline \multirow[t]{2}{*}{ MTRA2756G } & A & $192(80.3)$ & $160(81.2)$ & Ref & Ref \\
\hline & $\mathrm{G}$ & $47(19.7)$ & $37(18.8)$ & $1.06(0.66-1.71)$ & $1.22(0.73-2.04)$ \\
\hline \multirow[t]{2}{*}{ MTRRA66G } & A & $115(48.5)$ & $86(43.6)$ & Ref & Ref \\
\hline & $\mathrm{G}$ & $124(51.5)$ & $111(56.3)$ & $1.39(0.95-2.03)$ & $1.55(1.03-2.35)^{*}$ \\
\hline \multirow[t]{2}{*}{ CBS844ins68 } & - & $218(91.2)$ & $180(91.4)$ & Ref & Ref \\
\hline & + & $21(8.8)$ & $17(8.6)$ & $1.02(0.52-1.99)$ & $1.03(0.50-2.11)$ \\
\hline \multirow[t]{2}{*}{$R F C-1 \mathrm{~A} 80 \mathrm{G}$} & A & $139(58.1)$ & $126(63.9)$ & Ref & Ref \\
\hline & G & $100(41.8)$ & $71(36.1)$ & $1.27(0.87-1.88)$ & $1.40(0.92-2.13)$ \\
\hline
\end{tabular}

*Adjusted $p=0.03$.

interaction between different polymorphisms may totally modify their individual effects [24].

The present study showed that maternal polymorphisms in genes MTR, MTRR, RFC and CBS are not associated with increased risk of DS children when independently analyzed. The combination of one or more of these polymorphisms, however, results in an increased risk for DS, suggesting the existence of a synergistic relationship among them in a multifactorial way. This analysis showed that mothers of DS children have a tendency to present more risk genotypes than mothers without DS children. Furthermore, increasing the number of risk genotypes seems to result in a proportional increase in risk for DS, mainly when adjusted for age. It is important to stress that the size of the sample did not allow for detection of a possible association for mothers with four risk genotypes.

Several studies have analyzed SNPs related to folate metabolism as maternal DS risk factors, yet few of them utilized multivariate analysis to determine if those mutations and their interactions increase the risk for DS. Hobbs and colleagues, in 2000, reported an association between polymorphisms of genes $M T H$ $F R$ and $M T R R$ as a risk factor for DS when genotypes were analyzed independently (ORs $=1.91$ and 2.57; 95\%CI 1.19-3.05 and 1.33-4.99) or combined $(\mathrm{OR}=4.08 ;$ IC $95 \%=1.98-8.56)$ [15]. A similar study showed that risk for DS was higher when polymorphisms of MTHFR and MTRR genes were combined (OR $=2.98$; 95\% IC 1.19-7.46) but not for individual polymorphisms [27]. Furthermore, the association between altered folate metabolism and DNA hypomethylation supports the hypothesis that increased frequency of the MTHFR and MTRR combination observed in this study may be associated with chromosomal nondisjunction and DS. The variants of these enzymes could alter downstream methylation reactions leading to DNA hypomethylation. The reduction of methyl groups could influence chromosomal segregation and lead to the occurrence of trisomy of 21 [21,27]. In the present study we have observed that the same combinations could have different effects between cas- 
es and controls, confirming that the interaction between these polymorphisms may modify their individual effect, and that some of these effects may be different in mothers of DS children.

Recent investigations into other polymorphisms in folate/homocysteine metabolism have been conducted. Chango and colleagues [11], analyzed the role of polymorphisms in genes MTHFR, MTR, MTRR, CBS, and $R F C$, and did not show statistically significant differences for the distribution of these genotypes among control and case groups. The role of the combined genotypes as risk factors for DS was also investigated, with negative results. The same polymorphisms were also studied by another research group [30], but only for the $M T H F R$ and $R F C$ genes. The results showed evidence of independent and combined associations as risk factors for DS. Likewise, another study observed an association between the MTRR A66G polymorphism as a maternal risk factor for DS (OR 2.21; 95\% CI 1.114.40) [28].

In Brazil, Silva and colleagues [31] investigated polymorphisms in genes MTHFR, MTR, MTRR, and $C B S$ among 154 mothers with DS children and obtained results similar to ours. Only the polymorphism C677T of the MTHFR gene was associated with increased risk for DS; yet when the five polymorphisms were combined, a significantly higher number of polymorphic alleles were seen in mothers with DS children than in control mothers, corroborating with our data. Another Brazilian research group analyzed polymorphisms in genes MTHFR, MTR, CBS, RFC-1, and TC through a case-control study (114 DS mothers) and did not find any influence of these polymorphisms on DS susceptibility. Although our findings are similar to that of Silva and colleagues, some factors may have contributed to the inconsistencies between these Brazilian studies and ours, namely: the smaller sample size, control selection, and ethnic mixture of our study population. Despite these differences, data from these and others studies are important to provide information for metaanalyses to reveal the importance of these polymorphisms, even when they are combined.

Since advanced maternal age is an important risk factor for DS, we also analyzed the genotypic distribution of these polymorphisms according to mothers' age at childbirth $(<35$ or $\geqslant 35$ years old $)$, totalizing 118 case mothers and 168 control mothers. The results did not show significant differences in the distribution of genotypes among case and control mothers (data not shown), supporting the adjustment for age results (Table 1). According to Zintzaras [35], maternal age may represent an independent risk factor associated with increased incidence of DS. The lower frequency of DS in children of younger mothers, however, does not exclude the possibility that they may have a DS child when they are older. A meta-analysis considering the role of age in the association of polymorphisms of genes involved in folate metabolism may provide more conclusive results.

Some limitations of our study must be acknowledged. First, our study population was restricted to white women because of known differences in the distribution of genotypes according to ethnicity $[11,15$, 27]. Thus, our findings may not be generalized to women of other ethnicities or populations given the evidence of discordant conclusions in studies of different geographic regions. The discrepant results observed in different populations may also reflect the interactions existing between genetic and environmental factors implicated in folate metabolism [18]. Second, gene-environment interactions were not analyzed in this study. Risk factors may depend on genetic polymorphisms or on the gene-environment interaction represented by genotypes and dietary habits, in particular on the use of folic acid, which may be crucial for maintaining the effects of these polymorphisms [24]. Thus, the meaning of MTHFR and MTRR genotypes interaction found in this study in terms of specific metabolic biomarkers such as plasma homocysteine, folate, and $\mathrm{B}_{12}$ levels would increase the power to detect its significant impact on DS risk.

Based on these results we can conclude that: a) The polymorphisms studied cannot be considered as risk factors by themselves, corroborating with the multifactorial trait concerning the etiology of human nondisjunction. The current opinion is that the presence of a single polymorphism of a gene participating in folate metabolism would be insufficient to increase the risk of having a child with DS [3,6,12,15,24,30,31]. b) Our results are consistent with other studies showing an association between combined gene polymorphisms involved in folate metabolism and risk for DS; the combined presence of two or more polymorphisms in the genome increase the risk of DS in our population, showing the importance of their gene-gene interaction. c) An interaction of MTHFR and MTRR polymorphism is evident in our study; it is plausible since both genes work in the methylation pathway, disestablishing it and contributing to nondisjunction events. d) Data presented here will be important for future pooled analysis and meta-analysis to test additional gene-gene interactions with larger sample sizes and greater sta- 
tistical power. Most reports are based on small samples. It is important to stress that the number of DS mothers included in the present study, with correspondent ethnic and socio-demographic background in case and control groups, is, to our knowledge, the largest reported until now. More rigorous studies investigating combinations between genetic and environmental factors are needed to establish the role of polymorphisms in folate/homocysteine metabolism genes as risk factor for non-disjunction.

\section{Acknowledgments}

We are grateful to all the families who participated in this study. We also gratefully acknowledge the support of APAE professionals in the recruitment of families. This study was supported by the CNPq (Conselho Nacional de Desenvolvimento Científico e Tecnológico), FIPE/HCPA (Fundo de Incentivo a Pesquisa e Eventos) and Projeto Milênio (number 420019/05-7).

\section{References}

[1] S.E. Antonarakis, M.B. Petersen, M.G. McInnis, P.A. Adelsberger, A.A. Schinzel, F. Binkert, C. Pangalos, O. Raoul, S.A. Slaugenhaupt and M. Hafez, The meiotic stage of nondisjunction in trisomy 21: determination by using DNA polymorphisms, Am J Hum Genet 50 (1992), 455-550.

[2] L.B. Bailey, New standard for dietary folate intake in pregnant women, Am J Clin Nutr 71 (2000), 1304S-1307S.

[3] J.M. Biselli, E.M. Goloni-Bertollo, B.L. Zampieri, R. Haddad, M.N. Eberlin and E.C. Pavarino-Bertelli, Genetic polymorphisms involved in folate metabolismand elevated plasma concentrations of homocysteine: maternal risk factors for Down syndrome in Brazil, Genet Mol Res 7 (2008), 33-42.

[4] B.C. Blount, M.M. Mack, C.M. Wehr, J.T. MacGregor, R.A. Hiatt, G. Wang, S.N. Wickramasinghe, R.B. Everson and B.N. Ames, Folate deficiency causes uracil misincorporation into human DNA and chromosome breakage: implications for cancer and neuronal damage, Proc Natl Acad Sci USA 94 (1997), 3290-3295.

[5] K. Boduroğlu, Y. Alanay, B. Koldan and E. Tunçbilek, Methylenetetrahydrofolate reductase enzyme polymorphisms as maternal risk for Down syndrome among Turkish women, Am J Med Genet 127A (2004), 5-10.

[6] P. Bosco, R.M. Guéant-Rodriguez, G. Anello, C. Barone, F. Caraci, A. Romano, C. Romano and J.L. Guéant, Methionine synthase (MTR) 2756 (A -> G) polymorphism, double heterozygosity methionine synthase 2756 AG/methionine synthase reductase (MTRR) 66 AG, and elevated homocysteinemia are three risk factors for having a child with Down syndrome, Am J Med Genet 121 (2003), 219-224.

[7] A.P.C. Brandalize, E. Bandinelli, P.A. Santos, I. Roisenberg and L. Schuller-Faccini, Evaluation of C677T and A1298C Polymorphisms of the MTHFR Gene as Maternal Risk Factors for Down Syndrome and Congenital Heart Defects, Am J Med Genet 1267 (2009), 9-17.
[8] C.A. Brown, K.Q. McKinney, J.S. Kaufman, R.A. Gravel and R. Rozen, A common polymorphism in the methionine synthase reductase increases risk of premature coronary artery disease, J Cardiov Risk 7 (2000), 197-200.

[9] C. Butler, A.J. Knox, J. Bowersox, S. Forbers and D. Paterson, The production of transgenic mice expressing human cysthathionine beta-synthase to study Down syndrome, Behav Genet 36 (2006), 429-438.

[10] B. Chadefaux-Vekemans, M. Coudé, F. Muller, J.F. Oury, A. Chabli, J. Jaïs and P. Kamoun, Methylenetetrahydrofolate reductase polymorphism in the etiology of Down syndrome, Pediatr Res 51 (2002), 766-767.

[11] A. Chango, N. Fillon-Emery, C. Mircher, H. Bléhaut, D. Lambert, B. Herbeth, S.J. James, M.O. Réthoré and J.P. Nicolas, No association between common polymorphisms in genes of folate and homocysteine metabolism and the risk of Down's syndrome among French mothers, Br J Nutr 94 (2005), 166169.

[12] F. Coppedè, G. Marini, S. Bargagna, L. Stuppia, F. Minichilli, I. Fontana, R. Colognato, G. Astrea, G. Palka and L. Migliore, Folate gene polymorphisms and the risk of Down syndrome pregnancies in young Italian women, Am J Med Genet 140 (2006), 1083-1091.

[13] F. Coppedè, The complex relationship between folate/homocysteine metabolism and risk of Down syndrome, Mut Res 682 (2009), 54-70.

[14] P. Goyette, J.S. Sumner, R. Milos, A.M. Duncan, D.S. Rosenblatt, R.G. Matthews and R. Rozen, Human methylenetetrahydrofolate reductase: isolation of cDNA, mapping and mutation identification, Nat Genet 7 (1994), 195-200.

[15] C.A. Hobbs, S.L. Sherman, P. Yi, S.E. Hopkins, C.P. Torfs, R.J. Hine, M. Pogribna, R. Rosen and S.J. James, Polymorphisms in genes involved in folate metabolism as maternal risk factors for down syndrome, Am J Hum Genet 67 (2000), 623-630.

[16] C.A. Hobbs, M.A. Cleves, R.M. Lauer, S. Melnyk, Y. Lu, S. Malik and M.A. Cleves, Preferential transmission of the MTHFR 677 T allele to infants with Down syndrome: implications for a survival advantage, Am J Med Genet 113 (2002), 9-14.

[17] S.J. James, M. Pogribna, I.P. Pogribny, S. Melnyk, R.J. Hine, J.B. Gibson, P. Yi, D.L Tafoya, D.H. Swenson, V.L. Wilson and D.W. Gaylor, Abnormal folate metabolism and mutation in the methylenetetrahydrofolate reductase gene may be maternal risk factors for Down syndrome, Am J Clin Nutr 70 (1999), 495-501.

[18] S.J. James, Maternal metabolic phenotype and risk of down syndrome: beyond Genetics, Am J Med Genet 127 (2004), $1-4$.

[19] L.A. Kluijtmans, L.P. Van Der Heuvel, G.H. Boers, P. Frosst, E.M. Stevens, B.A. Van Oost, F.J. Trijbels and R.I. Rozen, Molecular genetic analysis in mild hyperhomocysteinemia: A common mutation in methylenetetrahydrofolate reductase gene is a genetic risk for cardiovascular disease, Am J Hum Genet 58 (1996), 35-41.

[20] E. Krivchenia, C.A. Huether, L.D. Edmonds, D.S. May and S. Guckenberger, Comparative epidemiology of Down syndrome in two United States populations, Am J Epidemiol 137 (1993), $815-828$.

[21] K.M. Lahiri and Jr. Nurnberger, A rapid non-enzymatic method for the preparation of HMW DNA from blood for RFLP studies, Nucleic Acids Res 19 (1991), 5444.

[22] D. Leclerc, E. Campeau, P. Goyette, C.E. Adjalla, B. Christensen, M. Ross, P. Eydoux, D.S. Rosenblatt, R. Rozen and R.A. Gravel, Human methionine synthase: cDNA cloning and 
identification of mutations in patients of the cblG complementation group of folate/cobalamin disorders, Hum Mol Genet $\mathbf{5}$ (1996), 1867-1874.

[23] D. Leclerc, A. Wilson, R. Dumas, C. Gafuik, D. Song, D. Watkins, H.H. Heng, J.M. Rommens, S.W. Scherer, D.S. Rosenblatt and R.A. Gravel, Cloning and mapping of a cDNA for methionine synthase reductase, a flavoprotein defective in patients with homocystinuria, Proc Natl Acad Sci USA 95 (1998), 3059-3064.

[24] M.L. Martínez-Frías, B. Pérez, L.R. Desviat, M. Castro, F. Leal, L. Rodríguez, E. Mansilla, M.L. Martínez-Fernández, E. Bermejo, E. Rodríguez-Pinilla, D. Prieto and M. Ugarte, Maternal polymorphisms 677C-T and 1298A-C of MTHFR, and 66A-G MTRR genes: is there any relationship between polymorphisms of the folate pathway, maternal homocysteine levels, and the risk for having a child with Down syndrome? Am J Med Genet 140 (2006), 987-997.

[25] N.A. Meguid, A.A. Dardir, M. Khass, L.E. Hossieny, A. Ezzat and M.K. El Awady, MTHFR genetic polymorphisms as a risk factor in Egyptian mothers with Down syndrome children, Dis Markers 24 (2008), 19-26.

[26] T.T Nguyen, D.L. Dyer, D.D. Dunning, S.A. Rubin, K.E. Grant and H.M. Said, Human intestinal folate transport cloning, expression and distribution of complementary RNA, Gastroenterology 112 (1997), 783-791.

[27] V.B. O'Leary, A. Parle-McDermott, A.M. Molloy, P.N. Kirke, Z. Johnson, M. Conley, J.M. Scott and J.L. Mills, MTRR and MTHFR polymorphism: Link to Down syndrome? Am J Med Genet 107 (2002), 151-155.

[28] E. Pozzi, P. Vergani, L. Dalprà, R. Combi, D. Silvestri, F. Crosti, M. Dell'Orto and M.G. Valsecchi, Maternal polymorphisms for methyltetrahydrofolate reductase and methionine synthetase reductase and risk of children with Down syn- drome, Am J Obstetr Gynecol 6 (2009), 636.e1-e6.

[29] A.K. Rai, S. Singh, S. Mentha, A. Kumar, L.K. Pandey and R. Raman, MTHFR C677T and A1298C polymorphisms are risk factors for Down's Syndrome in Indian mothers, $\mathrm{J} \mathrm{Hum}$ Genet 51 (2006), 278-283.

[30] I. Scala, B. Granese, M. Sellitto, S. Salome, A. Sammartino, A. Pepe, P. Mastoiacovo, G. Sebastio and G. Andria, Analysis of seven maternal polymorphisms of genes involved in homocysteine/folate metabolism and risk of Down Syndrome offspring, Genet Med 8 (2006), 409-416.

[31] L.R. Silva, N. Vergani, L.C. Galdieri, M.P.E. Porto, S.B. Longhitano, D. Brunoni, V. D'Almeida and A.B. Alvarez Perez, Relationship between polymorphisms in genes involved in homocysteine metabolism and maternal risk for Down syndrome in Brazil, Am J Med Genet 135 (2005), 263-267.

[32] L. Stuppia, V. Gatta, A.R. Gaspari, I. Antonucci, E. Morizio, G. Calabrese and G.Palka, C677T mutation in the 5,10MTHFR gene and risk of Down syndrome in Italy, Eur J Hum Genet 10 (2002), 388-390.

[33] N.M. Van der Put, E.F. van der Molen, L.A. Kluijitmans, S.G. Heil, J.M. Trijbels, T.K. Eskes, D. Van OppenraaijEmmerzaal, R. Banerjee and H.J. Blom, Sequence analysis of the coding region of human methionine synthase: relevance to hyperhomocysteinaemia in neural-tube defects and vascular disease, QJM 90 (1997), 511-517.

[34] W.C. Winkelmayer, C. Eberle, G. Sunder-Plassmann and M. Fodinger, Effects of the glutamate carboxypeptidase II (GCP2 $1561 \mathrm{C}>\mathrm{T}$ ) and reduced folate carrier (RFC1 80G $>\mathrm{A}$ ) allelic variants on folate and total homocysteine levels in kidney transplant patients, Kidney Int 63 (2003), 2280-2285.

[35] E. Zintzaras, Maternal gene polymorphisms involved in folate metabolism and risk of Down syndrome offspring: a meta analysis, J Hum Genet 52 (2007), 943-953. 


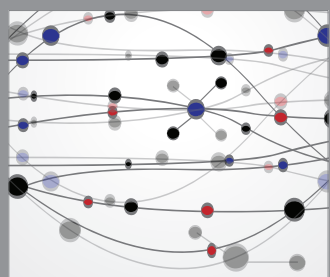

The Scientific World Journal
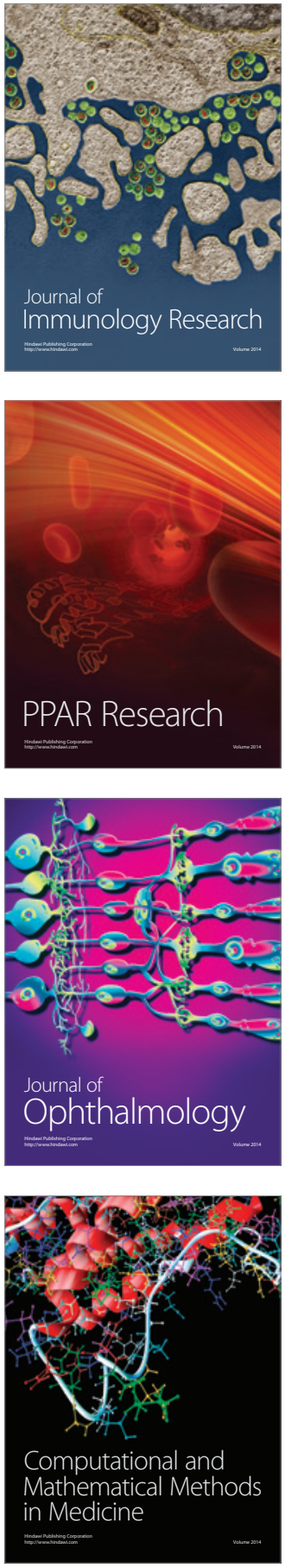

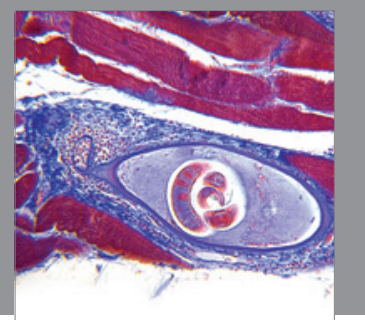

Gastroenterology

Research and Practice
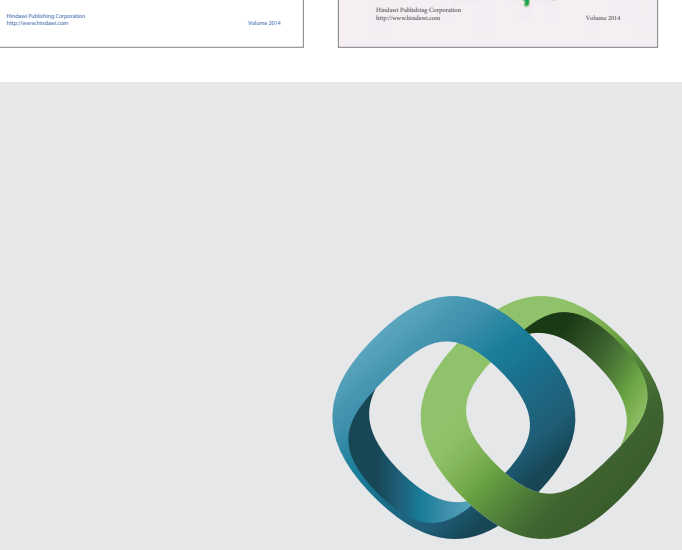

\section{Hindawi}

Submit your manuscripts at

http://www.hindawi.com
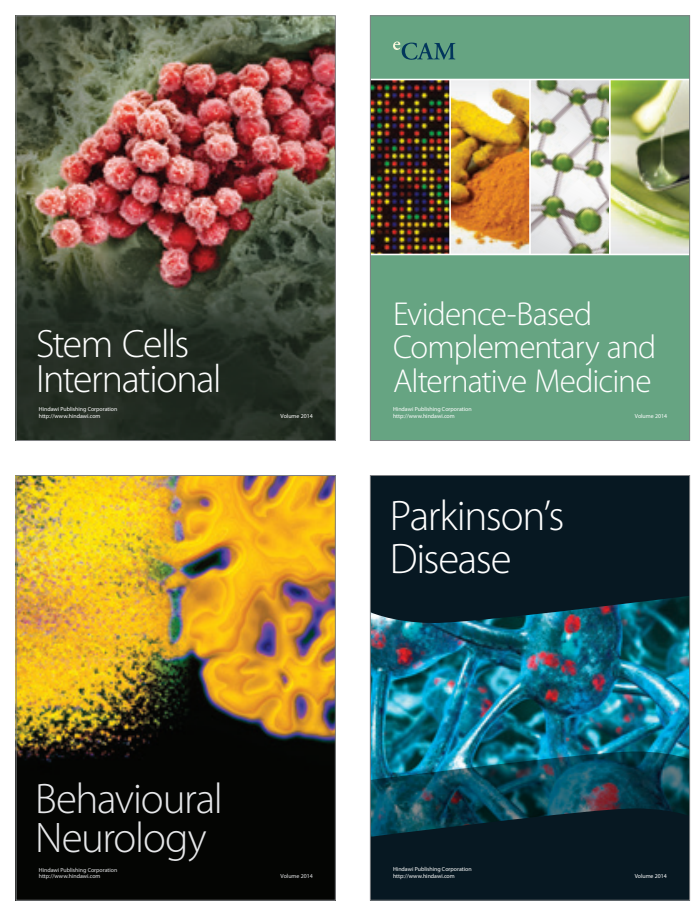

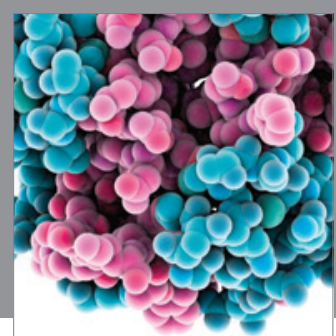

Journal of
Diabetes Research

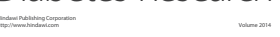

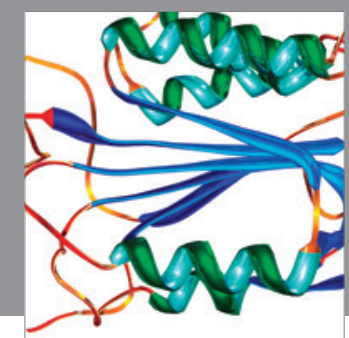

Disease Markers
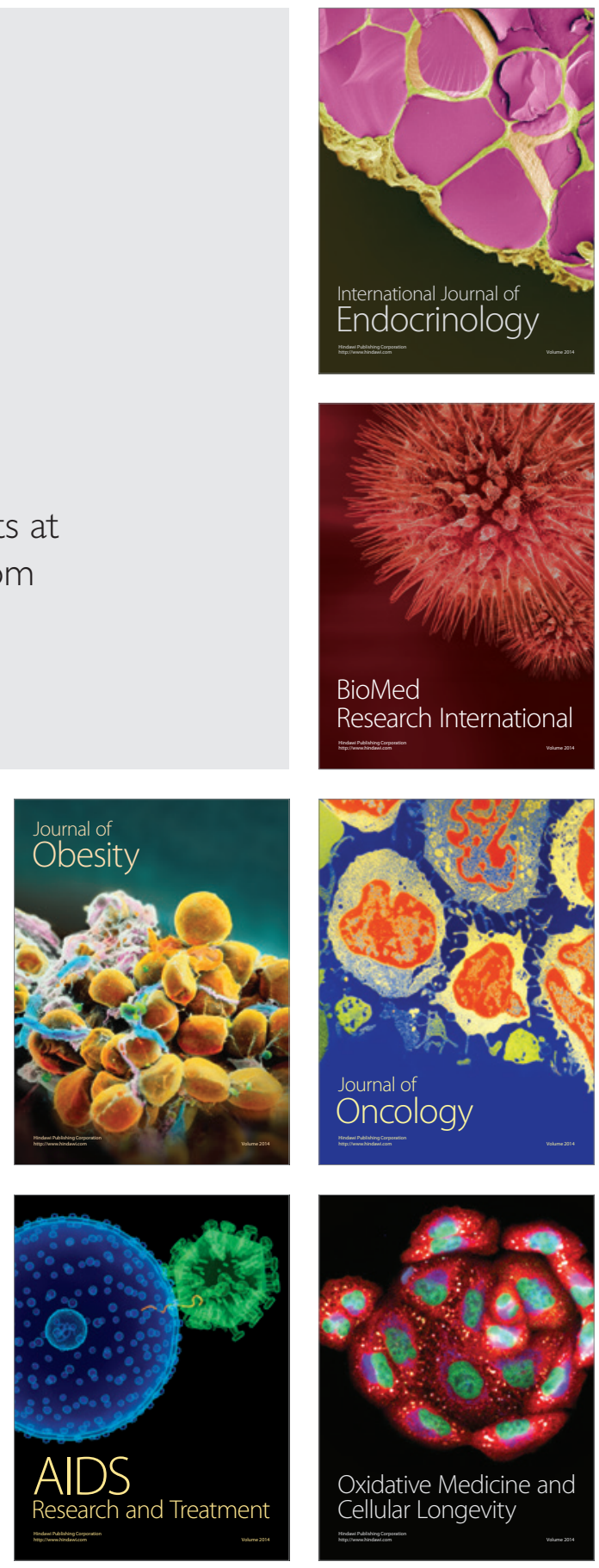